\title{
Incidence of adverse drug reactions in a paediatric ward of a Malaysian hospital: A prospective observational study
}

\author{
Muslimah Ithnin ${ }^{1}$, Mohd Dzulkhairi Mohd Rani ${ }^{1}$, Zuraidah Abd Latif ${ }^{2}$, Paveethra \\ a/p Kani ${ }^{3}$, Asmalita Syaiful ${ }^{1}$, Tengku Amatullah Madeehah Tengku Mohd ${ }^{1}$, \\ Khairun Nain Nor Aripin ${ }^{1}$ \\ ${ }^{1}$ Faculty of Medicine and Health Sciences, Universiti Sains Islam Malaysia, Menara B, Pandan Indah 55100 Kuala Lumpur, \\ ${ }^{2}$ Pediatric Department, ${ }^{3}$ Pharmacy Department, Hospital Ampang, 68000 Selangor, Malaysia
}

${ }^{\star}$ For correspondence: Email: khairun@usim.edu.my; Fax: +603 42892477

Sent for review: 13 July 2017

Revised accepted: 18 June 2018

\begin{abstract}
Purpose: To investigate the incidence, characteristics and risk factors of adverse drug reactions (ADRs) in hospitalized children in a Malaysian hospital.

Methods: Patients admitted to the Paediatric Department of Hospital Ampang in Kuala Lumpur, Malaysia were monitored for occurrence of ADRs by spontaneous reporting or daily review of their case notes. Characteristics of ADRs were categorised and ADRs were analysed for causality, severity and preventability. Multivariate analyses were performed to determine associations between certain selected risk factors and $A D R$ occurrence.

Results: In 423 paediatric patients admitted in Hospital Ampang (436 admissions), the ADR incidence rate was $8.0 \%(95 \% \mathrm{Cl}, 5-11 \%)$. The most commonly involved medications were systemic antibacterial drugs (77.4\%). About $61.3 \%$ of the ADRs were of probable causality and $12.9 \%$ were definitely preventable. No severe ADRs were detected, with $41.9 \%$ being moderate and $58.1 \%$ being mild, based on a severity scale. Younger children $(O R=3.387,95 \% \mathrm{Cl}, 1.377,8.334)$ and the number of systemic antibacterial drugs given $(O R=1.469,95 \% \mathrm{Cl} 1.201,1.798)$ were potential risk factors associated with ADRs.

Conclusion: ADRs occur at a significant rate in the Malaysian children admitted to the hospital studied. Further studies are needed to provide drug safety data for the paediatric population in Malaysia.
\end{abstract}

Keywords: Adverse drug reaction, Children, Paediatric, Drug safety

\begin{abstract}
This is an Open Access article that uses a funding model which does not charge readers or their institutions for access and distributed under the terms of the Creative Commons Attribution License (http://creativecommons.org/licenses/by/4.0) and the Budapest Open Access Initiative (http://www.budapestopenaccessinitiative.org/read), which permit unrestricted use, distribution, and reproduction in any medium, provided the original work is properly credited.
\end{abstract}

Tropical Journal of Pharmaceutical Research is indexed by Science Citation Index (SciSearch), Scopus, International Pharmaceutical Abstract, Chemical Abstracts, Embase, Index Copernicus, EBSCO, African Index Medicus, JournalSeek, Journal Citation Reports/Science Edition, Directory of Open Access Journals (DOAJ), African Journal Online, Bioline International, Open-J-Gate and Pharmacy Abstracts

\section{INTRODUCTION}

The World Health Organisation (WHO) defines an ADR as 'a response to a drug which is noxious, and unintended and which occurs at doses normally used in man for prophylaxis, diagnosis or therapy of disease, or for the modification of physiological function' [1]. ADRs can result in hospitalisation, increased length of hospital stay and charges, diminished quality of life, disability and in-hospital death [2].

ADRs remain a hazard in the medical treatment of children where previous systematic reviews 
have estimated ADR incidence ranging from 1-11 $\%$ affecting paediatric patients [3]. A recent systematic review of 102 studies showed that ADRs caused between $0.4-10.3 \%$ of hospital admissions in children, while the incidence of ADRs was between $0.6-16.8 \%$ in hospitalised children [4].

ADR data from Malaysia is sparse but emerging. A multinational surveillance study published in 2012 found that the ADR incidence in Malaysian paediatric patients was second highest at $19.1 \%$, based on a single study ward [5]. Furthermore the Malaysian group had the highest incidence of serious ADRs at $7.6 \%$, among the 5 participating countries. ADRs were the cause of admission in $1.7 \%$ of the children admitted to the Malaysian study ward. Another study analysed paediatric ADRs reported to the Malaysian drug control authority between 2000 and 2013 and found a dramatic increase in paediatric ADRs reported by healthcare personnel, from 115 reports in 2000 to 3527 in 2011 [6]. Slightly over half of the paediatric ADRs reported were vaccine related.

Adequate information obtained from ADRs can help healthcare professionals to take measures to avoid or diminish their effects in the clinical setting. The most fundamental assessment is to determine the causality of the drug involved. Despite a number of existing methods that have been developed to determine causality, only 71 $\%$ of paediatric ADR studies performed causality assessment. Even fewer studies performed other assessments such as severity (34 \%) and avoidability (19\%) that can provide valuable data to inform strategies to lessen the risk of ADRs [5].

This study aims to provide further data on the incidence of paediatric ADRs occurring in Malaysian children admitted to hospital and to identify possible risk factors. Another goal is to provide further ADR information by performing causality, severity and preventability assessments using recognised methods.

\section{EXPERIMENTAL}

\section{Study design}

This was a prospective observational study conducted in a paediatric general ward in Hospital Ampang. Hospital Ampang is a general hospital located in Kuala Lumpur, the capital of Malaysia. The paediatric department comprised three wards, the neonatal intensive care unit (NICU), and general wards $4 \mathrm{~A}$ and $4 \mathrm{~B}$. Ward $4 \mathrm{~B}$ was selected as the study ward and consists of 40 beds. All patients admitted to the ward and were exposed to any medication were monitored actively for occurrences of any ADRs until they were discharged. The study was designed according to WHO CIOMS International Ethical Guidelines for Health-related Research Involving Humans [7]. Ethical approval (no. NMRR-141009-21335(IIR) was obtained from the Medical Research and Ethics Committee (MREC) of the Malaysian Ministry of Health and the study was registered in the National Medical Research Register (research ID: 21335).

\section{Study population}

The study population consisted of paediatric patients aged 12 years and below who were admitted to the study ward over a one month study period beginning $17^{\text {th }}$ August until $16^{\text {th }}$ September 2015. All medications received were recorded. However total parenteral nutrition (TPN), intravenous (IV) hydration fluids, electrolytes and oxygen therapy were excluded from medications recorded to have been given to the patients. The prescribed drugs were then classified based on Anatomical Therapeutic Chemical-ATC/DDD Index 2015 [8]. Each medication was considered only once per patient irrespective of whether the dose was changed or prescriptions repeated during the hospital stay.

\section{Data collection procedure}

ADRs were identified using a two-pronged approach as described below:

\section{i. Spontaneous reporting by healthcare personnel}

The ward staff including all doctors, staff nurses and the ward pharmacist were briefed on the definition, presentation and classification of ADRs during education sessions held on February 10 and March 12, 2016. Posters on the study were displayed on the ward. A box file containing the ADR reporting form was placed at the ward counter for staff to record any patients suspected to have ADRs. The box file was checked regularly by the study team and any reports were collected.

\section{ii. Daily progress notes review}

Hospital Ampang uses a computerised hospital information system where progress notes are created whenever a patient comes into contact with any member of the medical staff involved in patient care. The progress notes recorded by nurses and doctors in the computerised hospital 
information system for all eligible patients were screened daily by the study team to identify all potential ADRs. Any potential ADR was then recorded using the ADR reporting form.

All suspected ADRs from the reporting forms were reviewed by the research team. The team will review the patient notes, including laboratory data, and a consensus decision was made on whether the event fitted the definition of an ADR or was an ineligible occurrence such as a disease-related manifestation or progression, treatment failure, medication error or others.

\section{Data collection}

An ADR reporting form was developed by the research team. The form consisted of nine different sections on the demographic information of the child, suspected ADR and drug suspected, treatment outcome, medication details, ADR assessments, relevant test and laboratory data, any relevant notes or remarks and details of the reporter.

The following established international classifications were used to categorise the information recorded in the ADR reporting forms: WHO definitions for ADRs terminology [1], WHO Adverse Reaction Terminology (WHO-ART) for system-organ classes [9]. ATC/DDD Index 2015 classification for medications [8] and International classification of diseases version 10 (ICD-I0) for diagnoses [10].

\section{Assessment of ADRs}

The causality of ADRs was evaluated using Liverpool Adverse Drug Reaction Causality Assessment Tool [11]. This is a questionnairebased classification of the suspected ADRs as definite, probable, possible, or unlikely. ADR severity was assessed by Hartwig's Severity Assessment Scale which gives an overview of the severity of ADR whether it was mild, moderate, or severe based on a scale of 1-7 [12]. Preventability of the detected ADRs was assessed using the Modified Schumock and Thornton Preventability Scale [13].

The ADR assessments were assisted by mobile application tools or apps previously developed and published by the research team [14]. The application were downloaded and installed from Google Play Store into a tablet computer, the resulting assessments were then recorded in a database (see below). The applications used were Adverse Drug Reaction Causality, Adverse
Drug Reaction and Adverse Drug Rxn Preventability [14].

\section{Evaluation of ADR incidence}

The incidence of patients with ADRs was defined as the number of patients with an ADR divided by the number of patients receiving medications. The incidence of patients with ADR during hospitalisation was defined as the number of patients with at least one ADR during their hospitalisation divided by the total number of patients receiving medications during the study period. The incidence of ADR as a reason of admission was calculated using number of patients admitted due to an ADR divided by the total number of patients admitted during the study period of time.

The proportion of patients experiencing an ADR was defined as the number of patients with at least one ADR divided by the total number of patients in the study period. For the purpose of proportion and incidence calculations, all results were converted to percentages.

\section{Data analysis}

Data from each ADR reporting form were stored and analysed using SPSS version 20 [15]. Descriptive statistics was used to analyse the characteristics of the study population for gender, patient's age, length of stay, number of drugs prescribed, and ICD-10 classification for reported diagnosis and drug prescriptions category.

To evaluate the relationship between the risk factor and ADR occurrence as an outcome Pearson Chi-Square tests were done for categorical variables and Mann-Whitney $U$ test was used for continuous variables. A p-value less than 0.05 was considered statistically significant (two-tail).

Multivariate analysis were then performed incorporating all risk factor variables with $p$-value of $<0.05$. Multivariate logistic regression analyses were used to evaluate the influence of these risk factors variables on ADR occurrences. A p-value of $<0.05$ was considered statistically significant.

\section{RESULTS}

\section{Demographic profile of study population}

A total of 423 paediatric patients with 436 admissions fulfilled the inclusion criteria and were included in the study population. Of 423 
children, 247 (58.4\%) were male and 176 (41.6 $\%$ ) were female.

The median age of the study population was two years (IQR 1-5). When subdividing the patients by ages, patients were categorised based on the guideline on Clinical Investigation of Medicinal Products in the Paediatric Population; infants 28 days until below two years and children above two years until below twelve years [16]. Based on this age category, 207 of the patients was under the infant category while 216 was under children category. The majority of the patients were Malays (80.1\%) and another $19.9 \%$ were from other ethnic groups. The majority of the patients are also Malaysian citizens (92.4\%)

Total days of hospital stay for the patients in the study population was 1903 days with median three days (IQR 2-4) of stay. A total of 387 (91.5 $\%)$ of children received 1778 drugs during hospitalization with a median of four drugs per patient who received medications; IQR 2-6. The demographic characteristics of children included in the study are summarized in Table 1.

Based on the ICD-10 classification system, 'Respiratory system' diseases were the most commonly reported diseases ( $n=216$; $51.1 \%$ ) followed by 'Certain infectious and parasitic' diseases ( $\mathrm{n}=54 ; 12.8 \%$ ). Then 'Injury, poisoning and certain other consequences of external causes' and 'Symptoms, signs and abnormal clinical and laboratory findings, not elsewhere classified' diseases $(n=35 ; 8.3 \%)$.

\section{Drug prescriptions}

A total of 1778 prescribed drugs were recorded during the one month study period. The highest number of prescriptions was for systemic antibacterial drugs, J01 ( $\mathrm{n}=513 ; 28.9 \%$ ), followed by obstructive airway drugs, R03 ( $\mathrm{n}=$ $449 ; 25.3 \%)$ and drugs groups for analgesics, N02 ( $n=301 ; 16.9 \%)$.

The most frequently prescribed drug for systemic antibacterials was penicillin $(n=126)$, for obstructive airway drugs it was salbutamol ( $\mathrm{n}=$ 205) and for analgesics, paracetamol ( $n=289)$. The most frequently prescribed drug in the three highest drug groups is summarised in Table 2.

\section{ADR incidence}

From 423 patients and 387 patients who received medication, a total 34 of the patients experienced an ADR during the study period, ADRs caused 4 admissions to the hospital. The incidence of ADR as a cause of admission was $1.0 \%(95 \% \mathrm{Cl} 0-2 \%)$.

For the ADRs during hospital stay, 31 of the patients experienced an ADR following medication. The incidence of ADR during hospital stay was $8.0 \%(95 \% \mathrm{Cl} 5-11 \%)$. The proportion and incidence of patients experiencing ADRs is summarized in Table 3.

Table 1: Patient demographic characteristics

\begin{tabular}{|c|c|}
\hline Patient characteristics & Value \\
\hline $\begin{array}{l}\text { Number of patients (Number of } \\
\text { admissions) }\end{array}$ & $423(436)$ \\
\hline \multicolumn{2}{|l|}{ Patients by age groups, [n (\%)] } \\
\hline 1 months $-<2$ years & $207(48.9)$ \\
\hline (Infants) & $216(51.1)$ \\
\hline \multicolumn{2}{|l|}{$\begin{array}{l}\geq 2-<12 \text { years } \\
\text { (Children) }\end{array}$} \\
\hline Age (years), [median (IQR)] & $2(1-5)$ \\
\hline \multicolumn{2}{|l|}{ Gender, [n (\%)] } \\
\hline Male & $247(58.4)$ \\
\hline Female & $176(41.6)$ \\
\hline \multicolumn{2}{|l|}{ Ethnicity, [n (\%)] } \\
\hline Malay & $339(80.1)$ \\
\hline Chinese & $25(5.9)$ \\
\hline India & $19(4.5)$ \\
\hline Others & $40(9.5)$ \\
\hline \multicolumn{2}{|l|}{ Nationality, [n (\%)] } \\
\hline Malaysian & $391(92.4)$ \\
\hline Others & $32(7.6)$ \\
\hline $\begin{array}{l}\text { Length of stay (days), [median } \\
\text { (IQR)] }\end{array}$ & $3(2-4)$ \\
\hline $\begin{array}{l}\text { Number of patients who received } \\
\text { medications, [n (\%)] }\end{array}$ & $387(91.5)$ \\
\hline Total number of drugs prescribed & 1778 \\
\hline $\begin{array}{l}\text { Number of drugs prescribed per } \\
\text { patient, [median (IQR)] }\end{array}$ & $2(3-5)$ \\
\hline $\begin{array}{l}\text { Number of drugs prescribed per } \\
\text { patient, (only those with } \\
\text { medication) [median (IQR)] }\end{array}$ & $4(2-6)$ \\
\hline IQR = interquartile range & \\
\hline
\end{tabular}

\section{ADR characteristics}

The drug classes and the drugs involved in ADRs are summarized in Table 4. The systemic antibacterials were the drug group mostly involved with ADRs, with penicillin $(n=11)$ the most frequent drug associated with ADR. Among the clinical manifestation of ADRs caused by penicillin was diarrhoea, rash and thrombophlebitis. The second most frequently involved drug was erythromycin $(n=5)$ which cause diarrhoea and vomiting. The other drug classes involved in ADRs were antivirals $(n=2)$, immune sera and immunoglobulins $(n=2)$, anaesthetic $(n=2)$ and anti-inflammatory $(n=1)$ drugs. 
Table 2: Most frequently prescribed drugs for the three most common drug groups

\begin{tabular}{llc}
\hline $\begin{array}{l}\text { Drug group } \\
\text { (ATC classification) }\end{array}$ & Drug (no. of prescriptions) & Prescriptions (\%) \\
\hline Systemic antibacterial & Penicillin (126), Amoxicillin (42), Ampicillin (3), & $172(33.5)$ \\
(J01) & Phenoxymethylpenicillin (1), & \\
& Erythromycin (108), Azithromycin (44), & $163(31.8)$ \\
& Clarithromycin (11) & \\
& Cefuroxime (62) & $62(12.1)$ \\
& Ceftriaxone (13), Ceftazidime (6), Cefotaxime & $24(4.7)$ \\
& (3), Cefoperazone (2) & \\
& Others (92) & $92(17.9)$ \\
Obstructive airways drug & Sotal & $\mathbf{5 1 3}$ \\
(R03) & Salbutamol (205) & $205(45.7)$ \\
& Montelukast Sodium (48) & $48(10.7)$ \\
& Bromhexine (31) & $31(6.9)$ \\
Analgesics (N02) & Others (165) & $165(36.7)$ \\
& Total & $\mathbf{4 4 9}$ \\
& Paracetamol (289) & $289(96.0)$ \\
& Other (12) & $12(4.0)$ \\
\hline
\end{tabular}

ATC = Anatomical therapeutic chemical

Table 3: Proportion and incidence of patients experiencing ADR

\section{ADR proportion and incidence}

Proportion $^{\mathrm{a}}$ of patients with an ADR

Age 1 month $-<2$ year $(n=207)$

Age 2 year - $<12$ year $(n=216)$

Incidence ${ }^{\mathrm{b}}$ of patients with ADR

Incidence of ADR as a reason of admission

Incidence of ADR during hospitalisation

${ }^{a}$ Proportion takes into account all patients in the study period, $n=423 .{ }^{b}$ Incidence takes into account patients receiving medication during the study period, $n=387$. * 1 patient was admitted due to an ADR to azithromycin and then experienced another ADR with penicillin whilst hospitalised, counted as single in the calculation of total $A D R$ incidence

Table 4: Categories and types of drugs associated with adverse drug reactions

\begin{tabular}{|c|c|c|c|}
\hline $\begin{array}{l}\text { Drug group (ATC } \\
\text { classification) }\end{array}$ & $\begin{array}{l}\text { No. of } \\
\text { patients with } \\
\text { ADR }\end{array}$ & $\begin{array}{c}\text { Drugs (no. of ADR for each } \\
\text { causative reaction) }\end{array}$ & Examples of ADRs \\
\hline Antibacterials & 24 & $\begin{array}{l}\text { Penicillin (11), Erythromycin (5), } \\
\text { Pheroxymethylpenicillin (1), Amoxycillin } \\
\text { (1), Azithromycin (1), Cephalexin (1), } \\
\text { Cloxacillin (1), Imipenem (1), } \\
\text { Multiple antibiotic induced (2) }\end{array}$ & $\begin{array}{l}\text { Vomiting } \\
\text { (Erythromycin), } \\
\text { Diarrhoea (Penicillin), } \\
\text { Rash (Penicillin), } \\
\text { Thrombophlebitis } \\
\text { (Azithromycin) }\end{array}$ \\
\hline Antivirals & 2 & Acyclovir (2) & Diarrhoea (Acyclovir) \\
\hline $\begin{array}{l}\text { Immune Sera \& } \\
\text { Immunoglobulin }\end{array}$ & 2 & Immunoglobulin (2) & Thrombophlebitis \\
\hline Anaesthetics & 2 & General anaesthetic (1), Ketamine (1) & $\begin{array}{l}\text { Nausea (General } \\
\text { anaesthetic), } \\
\text { Drowsiness (Ketamine) }\end{array}$ \\
\hline Anti-inflammatory & 1 & Ibuprofen (1) & Nausea (Ibuprofen) \\
\hline
\end{tabular}

The associated ICD-10 diagnoses are shown in Table 5. From the 31 patients who developed ADRs, eighteen were diagnosed with 'diseases of respiratory system' and followed by six with 'certain infectious and parasitic diseases' and two each with 'diseases of the nervous system' and 'injury, poisoning and certain other consequences of external causes'.

\section{Causality, severity and preventability}

The causality assessment of the ADRs were as follows; $9.7 \%$ were assessed as definite, $61.3 \%$ were probable and $29.0 \%$ were possible. For the severity, $58.1 \%$ of the ADRs were mild and 41.9 $\%$ were moderate. None of ADRs were classed 
as a severe reaction. Most of the ADRs were classified as not preventable (74.2\%) while an equal percentage $(12.9 \%)$ of the ADRs were classified as definitely and probably preventable. The results of the ADR assessment of causality, severity and preventability are summarised in Table 6.

Table 6: Causality, severity and preventability of ADR

\begin{tabular}{lc}
\hline ADR Assessment & $\begin{array}{c}\text { No. of ADR (\%), } \\
\mathbf{n = 3 1}\end{array}$ \\
\hline Causality [n (\%)] $^{(\text {a) }}$ & $3(9.7)$ \\
$\quad$ Definite & $19(61.3)$ \\
Probable & $9(29.0)$ \\
Possible & \\
Severity [n (\%)] & \\
$\quad$ Mild & $18(58.1)$ \\
$\quad$ Moderate & $13(41.9)$ \\
Severe & $0(0.0)$ \\
Preventability[n (\%)] & \\
Definitely Preventable & $4(12.9)$ \\
Probably Preventable & $4(12.9)$ \\
Not Preventable & $23(74.2)$
\end{tabular}

${ }^{a}$ Causality scale according to Liverpool Adverse Drug Reaction Causality Assessment Tool [11]; ' Severity scale according to Hartwig's Severity Assessment Scale.[12]; ' Preventability scale according to Modified Schumock and Thornton Preventability Scale [13]

\section{Statistical modelling outcome}

The bivariate analysis showed that four of nine variables were significantly associated with the occurrence of ADRs. Logistic regression was performed to test effects of age, numbers of drug prescribed, being prescribed systemic antibacterial drugs and the number of systemic antibacterial prescribed on ADR occurrences during hospital stay. The results indicate that the predictors in the multivariable modelling included only two variables; age and number of systemic antibacterial prescribed. The multivariate model provided a statistically significant improvement over the constant-only-model, $x^{2}(2, N=387)=$ 24.526, $p<0.001)$.

The younger age of infants category (1 month until below 2 years old) was 3 times $(\mathrm{OR}=3.387$, $95 \% \mathrm{Cl}, 1.377$ to 8.334$)$ more likely to develop ADR during hospital stay. Since numbers of systemic antibacterial drugs was a quantitative numerical variable, an increase in one unit of systemic antibacterials increased ADR occurrences by 1.5 times $(\mathrm{OR}=1.469,95 \% \mathrm{Cl}$ 1.201).

The bivariate analysis for the associations between ADR occurrence and the potential risk factors and the results of the full model of multivariable analysis are shown in Table 7.

\section{DISCUSSION}

In the study, 31 out of 387 paediatric patients (8.0\%) experienced ADRs while in hospital. Although this incidence is lower than the previously reported ADR incidence in a Malaysian paediatric ward, it remains within the range of reported ADR incidence in paediatric patients [3]. When seen together with the increasing reporting of ADRs in the paediatric population in Malaysia, there appears to be growing evidence that Malaysian paediatric patients experience similar rates of ADRs with other children worldwide [4].

Table 5: Main diagnoses and ADRs occurrences

\begin{tabular}{|c|c|c|c|}
\hline Diagnoses (ICD-10 Classification) & $\begin{array}{c}\text { No. of } \\
\text { patients (\%), } \\
n=423\end{array}$ & $\begin{array}{c}\text { No. of } \\
\text { patients on } \\
\text { drug (\%), } \\
n=387\end{array}$ & $\begin{array}{l}\text { No. of patients } \\
\text { with ADR (\%) } \\
\qquad n=31\end{array}$ \\
\hline Diseases of the respiratory system & $216(51.1)$ & $212(54.8)$ & $18(8.5)$ \\
\hline Certain infectious and parasitic diseases & $54(12.8)$ & $41(10.6)$ & $6(14.6)$ \\
\hline Diseases of the nervous system & $13(3.1)$ & $12(3.1)$ & $2(16.6)$ \\
\hline $\begin{array}{l}\text { Injury, poisoning and certain other } \\
\text { consequences of external causes }\end{array}$ & $35(8.3)$ & $31(8.0)$ & $2(6.5)$ \\
\hline $\begin{array}{l}\text { Diseases of the blood and blood-forming } \\
\text { organs and certain disorders involving the } \\
\text { immune mechanism }\end{array}$ & $3(0.7)$ & $3(0.8)$ & $1(33.3)$ \\
\hline $\begin{array}{l}\text { Symptoms, signs and abnormal clinical and } \\
\text { laboratory findings, not elsewhere classified }\end{array}$ & $35(8.3)$ & $33(8.5)$ & $1(3.0)$ \\
\hline Mental and behavioural disorders & $3(0.7)$ & $1(0.3)$ & $1(100)$ \\
\hline
\end{tabular}


Table 7: Risk factors of ADRs in hospitalised children

\begin{tabular}{|c|c|c|c|c|}
\hline Risk factor & $\mathrm{OR}^{\mathrm{a}}(95 \% \mathrm{Cl})$ & p-value & AOR $^{b}(95 \% C l)$ & p-value \\
\hline Age (Infant vs Children) & $3.924(1.649,9.342)^{c}$ & $0.001^{*}$ & $3.387(1.377,8.334)$ & $0.008^{*}$ \\
\hline Gender (Female vs Male) & $1.294(.602,2.781)^{c}$ & 0.509 & & \\
\hline $\begin{array}{l}\text { Ethnicity (Non-Malay vs } \\
\text { Malay) }\end{array}$ & $0.780(.323,1.888)^{\mathrm{C}}$ & 0.581 & & \\
\hline $\begin{array}{l}\text { Nationality (Malaysian vs } \\
\text { Others) }\end{array}$ & $2.049(.663,6.337)^{\mathrm{c}}$ & 0.264 & & \\
\hline $\begin{array}{l}\text { Number of drugs } \\
\text { prescribed }\end{array}$ & $1.086(1.012,1.165)^{d}$ & $<0.001^{*}$ & $0.889(.756,1.046)$ & 0.155 \\
\hline $\begin{array}{l}\text { Receiving J01 Drug (No vs } \\
\text { Yes) }\end{array}$ & $3.800(1.130,12.774)^{\mathrm{C}}$ & $0.021^{*}$ & $1.304(0.337,5.038)$ & 0.071 \\
\hline $\begin{array}{l}\text { Number of J01 drugs } \\
\text { prescribed }\end{array}$ & $1.536(1.244,1.897)^{a}$ & $<0.001^{*}$ & $1.469(1.201,1.798)$ & $<0.001^{*}$ \\
\hline $\begin{array}{l}\text { Certain infectious and } \\
\text { parasitic disease (No vs } \\
\text { Yes) }\end{array}$ & $2.201(.845,5.731)^{\mathrm{C}}$ & 0.121 & & \\
\hline $\begin{array}{l}\text { Disease of the respiratory } \\
\text { system (No vs Yes) }\end{array}$ & $1.156(.550,2.431)^{\mathrm{C}}$ & 0.702 & & \\
\hline $\begin{array}{l}{ }^{a} \text { Risk factors are presente } \\
\text { adjusted odds ratios (ORs } \\
\text { number of drugs prescribec } \\
\text { drug prescribed (J01)]; }{ }^{C} \mathrm{Pe}\end{array}$ & Chi-Square tests: $d$ & $\begin{array}{l}\text { drugs (J } \\
\text { itnev U }\end{array}$ & $\begin{array}{l}\text { number of system } \\
\text { gnificant at } p<0.05\end{array}$ & $\begin{array}{l}\text { „ll model } \\
\text { rs [age, } \\
\text { bacterial }\end{array}$ \\
\hline
\end{tabular}

According to data, the most common classes of drugs involved in ADRs were systemic antibacterial, antivirals, immune sera and immunoglobulins, anaesthetic and antiinflammatory drugs and the most commonly identified physical clinical presentation of ADRs were diarrhoea, vomiting, thrombophlebitis and skin rash. This is consistent with results of previous studies $[5,17]$.

Systemic antibacterial drugs antibiotics are the most widely prescribed drug category for hospitalized children [18]. The data shows that $74.7 \%$ of the patients in our study received at least one antibiotic medication during their hospital stay and $77.4 \%$ of the reported ADRs were related to this drug group, which is known to be frequently associated with ADRs [19]. In the study, the most common drug associated with ADRs was Penicillin. Although all ADRs related to systemic antibacterials in this study (as well as the previous Malaysian study [5]) were mild ADRs such as rashes and gastrointestinal upset, antibiotic use for hospitalized children should be optimized to reduce the risk of ADRs occurring. Furthermore, the rising spectre of antibiotic resistance most likely due to injudicious antibiotic use presents severe consequences [20]. Physicians should limit systemic antibacterial use only to children who would clearly benefit from the antibiotics, and the antibiotics should only be administered for the shortest effective duration.

The study results showed that $74 \%$ ADRs were not preventable and $26 \%$ were either definitely or probably preventable. Preventable ADRs could be attributed to improper dosage, inappropriate monitoring of the dose, drug-drug interactions or history of allergic reaction in past [13]. Causality, severity and preventability assessments of ADRs provide useful information in the effort to optimize paediatric drug prescribing. However such assessments are not universal in paediatric ADR studies [4]. These assessments can often be difficult to perform in the clinical setting especially when paediatric patients are often prescribed multiple drugs. Recently developed and existing assessment methodologies [11-13] should assist researchers in conducting ADR assessments but there is an increasing need for consensus building worldwide to allow meaningful comparisons of data coming out of paediatric ADR studies [21].

Results from our bivariate analysis showed several factors that predispose to ADRs in hospitalized children. It was found that younger age was significantly associated with ADR occurrences and the results of the full multivariate model analysis was also significant with infants or the younger age group three times more likely to develop an ADR. Previous studies have shown similar findings and it is thought that the developmental differences in pharmacokinetics and pharmacodynamics confer a higher risk of ADRs in neonates and younger children treated in hospital [22].

Several studies show that female children seemed to suffer a higher incidence of ADRs compared to boys. This may be due to the variation in gene expression and regulation causing differing therapeutic responses (pharmacodynamics and pharmacokinetics) and toxicity compared to the male sex [23]. The study 
shows no association between gender difference and ADR occurrences. The same finding was seen in the study conducted by Rashed et al [5] where included children in a Malaysian population showed no significant association of ADRs between genders. Further work is needed to determine if there is a gender predisposition in paediatric ADRs [24].

WHO recommends countries to generate paediatric safety data specific to the local populations to account for possible genetic differences relating to ADRs [25]. The research showed no association between ethnicity and citizenship with ADRs. Previous studies have demonstrated differences in ADR rates amongst the different ethnic groups in our local population. A study conducted in Singaporean children showed that children of Chinese descent were more likely to develop ADRs [17]. Future pharmacogenomic research will provide more insights especially on drugs associated with more serious ADRs.

In the bivariate analysis, numbers of medication prescribed show a significant relationship with ADRs. However in the full model of multivariate analysis, the numbers of medication prescribed is not significant. Numerous other ADR studies have shown that polypharmacy was associated with an increased risk of ADRs [4]. Both prescribing antibacterials and the numbers of the antibacterials prescribed show a significant association with ADR occurrences.

However, in the full model of multivariate regression analysis, only the factor of number of systemic antibacterials prescribed showed a significant relationship with ADR occurrences $(O R=1.469, p<0.001)$. Antibacterial drugs have been highlighted repeatedly as a high risk group that increase the risk of ADRs in children, to increase further when multiple systemic antibacterial drugs are used [26]. The findings reinforce that guidelines should be developed or updated to ensure judicious use of systemic antibacterial drugs in hospitalized children.

\section{Limitations of the study}

There are a few limitations that may affect the findings of the research. Only patients aged one month to twelve years old were included while neonates and adolescents were excluded. Thus, the ADR profile in Malaysian hospitalized children could not be fully explored. The sources used for detecting the adverse drug events in this study based on documented physician and nurse notes within the hospital computerised system. This was dependent on complete and accurate documentation by physicians and nurses. Symptoms or signs of some ADRs may be not be fully documented, especially during patient reviews in the evening or at night, therefore would be missed by the surveillance review. This could have reduced the size of the dataset.

To our knowledge this is the second study to determine the incidence of ADRs in children admitted to paediatric wards in a hospital in Malaysia. The first study was conducted back in 2009. Thus this study provides the most recent data on ADR incidence in hospitalized children aged 1 - 12 in Malaysia. They used logistic regression analysis to better understand the relationships between independent ADR predictors. Risk factors related to occurrence of ADRs could help identify patients with greater risk, in this case younger children, those given multiple systemic antibacterials and perhaps female patients. A better identification and understanding of these risk factors would enable avoidance measures to be taken to avoid ADRs.

\section{CONCLUSION}

This study found that the ADR incidence rate in children admitted to Hospital Ampang is $8 \%$ and that the associated risk factors were younger age and number of systemic antibacterials given. This is the second study of paediatric ADR incidence in Malaysia, however, the rate and characteristics of paediatric ADRs are broadly similar to studies conducted in other countries. Further studies on ADRs and drug safety in the Malaysian paediatric population are warranted in the light of these data.

\section{DECLARATIONS}

\section{Acknowledgement}

We would like to thank the Director General of the Ministry of Health for his permission to publish this article. We would like to thank all the staff of Department of Paediatrics, Ampang Hospital for their kind help in conducting the research. This study was funded by a grant from Ministry of Higher Education (MOHE) Malaysia under USIM/RAGS/FPSK/36/50314. The funders had no role in the study design, data collection and analysis, decision to publish, or preparation of the manuscript.

\section{Conflict of interest}

No conflict of interest is associated with this work. 


\section{Contributions of authors}

We declare that this work was done by the author(s) named in this article and all liabilities pertaining to claims relating to the content of this article will be borne by the authors. KN, MDMR and TAMTM conceived and supervised the study. MI and AS collected data from the ward. They, together with ZAL and PK assessed and analyzed potential ADRs. MI wrote the paper, while KN, MDMR, TAMTM edited the manuscript and gave the final approval. All authors contributed exclusively to the work presented in this paper.

\section{REFERENCES}

1. WHO. International Drug Monitoring: The role of the hospital. Geneva: WHO, 1969.

2. Lazarou J, Pomeranz BH, Corey PN. Incidence of adverse drug reactions in hospitalized patients a metaanalysis of prospective studies. JAMA 1998; 279 (15): 1200-1205.

3. Clavenna A, Bonati M. Adverse drug reactions in childhood: a review of prospective studies and safety alerts. Arch Dis Child 2009; 94 (9): 724-728.

4. Smyth RM, Gargon E, Kirkham J, Cresswell L, Golder S, Smyth $R$, Williamson $P$. Adverse drug reactions in children--a systematic review. PLOS ONE 2012; 7 (3): e24061.

5. Rashed AN, Wong ICK, Cranswick N, Hefele B, Tomlin S, Jackman J, Lee K, Hon KL, Ghaleb M, Chua SS, Hui TM, Rascher W, Neubert A. Adverse drug reactions in children - international surveillance and evaluation (ADVISE): A multicentre cohort study. Drug Safety 2012; 35(6): 481-494.

6. Rosli R, Ming LC, Abd Aziz N, Manan MM. A retrospective analysis of spontaneous adverse drug reactions reports relating to paediatric patients. PLOS One 2016; 11(6):e0155385.

7. Council for International Organizations of Medical Science (CIOMS) in collaboration with WHO. International Ethical Guidelines for Health-related Research Involving Humans. Geneva: WHO, 2016.

8. WHO collaborating centre for drug statistics methodology. ATC/DDD Index 2015. Available at: http://www.whocc.no/atc_ddd_index/.

9. The WHO adverse reaction terminology: terminology for coding clinical information in relation to drug therapy. 2003. Available at: http://www.umc-products. com/graphics/3036.pdf/.

10. International classification of diseases version 10. Available at: http://www.who.int/classifications/icd/en/.

11. Gallagher RM, Kirkham JJ, Mason JR, Bird KA, Peak M, Williamson PR, Nunn A, Turner MA, Pirmohamed $M$, Smyth $R L$. Development and inter-rater reliability of the
Liverpool adverse drug reaction causality assessment tool. PLoS One. 2011; 6(12): e28096.

12. Hartwig SC, Siegel J, Schneider PJ. Preventability and severity assessment in reporting adverse drug reactions. Am J Hosp Pharm 1992; 49: 2229-2232.

13. Mrugank BP, Hareesha RP. Prospective observational, non-randomized, parallel sequence study for assessment of adverse drug reactions due to chemotherapeutic treatment in different types of cancer patients. Int J Pharm Sci Res 2013; 4(1); 386-391.

14. Ithnin M, Mohd Rani MD, Abd Latif Z, Kani P, Syaiful A, Nor Aripin KN, Tengku Mohd TAM. Mobile App Design, Development, and Publication for Adverse Drug Reaction Assessments of Causality, Severity, and Preventability. JMIR Mhealth Uhealth 2017; 5(5) : e78.

15. IBM. Statistical package for social science. SPSS Vers. 20.0. 2011. Chicago:IBM.

16. International Committee on Harmonization (ICH). E 11 Clinical investigation of medicinal products in the paediatric population-EU: Note for guidance on clinical investigation of medicinal products in the paediatric population (CPMP/ICH/2711/99). 2000. London, UK.

17. Kidon MI, See Y. Adverse drug reactions in Singaporean children. Singapore Med J 2004; 45 (12): 574-577.

18. Rashed AN, Wong ICK, Wilton L, Tomlin S, Neubert A. Drug utilisation patterns in children admitted to a paediatric general medical ward in five countries. Drugs - Real World Outcomes 2015; 2(4):397-410.

19. Star K, Norén GN, Nordin K, Edwards IR. Suspected adverse drug reactions reported for children worldwide. Drug Safety 2011; 34(5): 415-428.

20. Piddock LJV. Reflecting on the final report of the O'Neill Review on Antimicrobial Resistance. The Lancet Infectious Diseases 2016; 16 (7): 767-768.

21. Cliff-Eribo KO, Sammons $H$, Choonara I. Systematic review of paediatric studies of adverse drug reactions from pharmacovigilance databases. Expert Opinion on Drug Safety 2016; 15 (10): 1321-1328.

22. Wood AJ, Kearns GL, Abdel-Rahman SM, Alander S, Blowey J, Leeder S, Kauffman R. Developmental pharmacology-drug disposition, action, and therapy in infants and children. N Engl $J$ Med 2003; 349 (12): 1157-1167.

23. Tran C, Knowles SR, LiU BA, Shear NH. Gender Differences in Adverse Drug Reactions. I Clin Pharmacol 1998; 38 (11): 1003-1009.

24. Franconi F, Brunelleschi S, Steardo L, Cuomo V. Gender differences in drug responses. Pharmacol Res 2007; 55 (2): 81-95.

25. WHO. Promoting safety of medicines for children. Switzerland: World Health Organization; 2007.

26. Rashed A, Wong IK, Cranswick N, Tomlin S, Rascher W, Neubert A. Risk factors associated with adverse drug reactions in hospitalised children: international multicentre study. Eur J Clin Pharmacol 2012; 68 (5): 801-810. 